This document is the accepted manuscript version of the following article:

Unsa1, E., Rücker, M., Berg, S., Barte1s, W. B., \& Bonnin, A. (2019). Imaging of compositional gradients during in situ emulsification using X-ray microtomography. Journal of colloid and Interface Science, 550, 159-169. https://doi.org/10.1016/j.jcis.2019.04.068

This manuscript version is made available under the CC-BY-NC-ND 4.0 license http://creativecommons.org/1icenses/by-nc-nd/4.0/

\title{
Imaging of compositional gradients during in-situ emulsification using X-ray micro-tomography
}

\author{
E. Unsal ${ }^{1 *}$, M. Ruecker ${ }^{1,2,3}$, S. Berg ${ }^{1,2,3}$, W.B. Bartels ${ }^{1,4}$, A. Bonnin ${ }^{5}$, \\ ${ }^{1}$ Shell Global Solutions International B.V., 2288 GS Rijswijk, NL \\ ${ }^{2}$ Department of Earth Science and Engineering, Imperial College London, SW7 2AZ UK \\ ${ }^{3}$ Department of Chemical Engineering, Imperial College London, SW7 2AZ UK \\ ${ }^{4}$ Earth Sciences department, Utrecht University, 3584 CD Utrecht, NL \\ ${ }^{5}$ Swiss Light Source, Paul Scherrer Institute, CH-5232 Villigen, Switzerland \\ *Corresponding author
}

\begin{abstract}
The rate of emulsification in surfactant/oil/water systems is influenced by transport of chemicals and mixing of the fluid phases. In porous media applications, complex flow regimes are generated due to three-dimensional connectivity and irregular cross-sections of the pores facilitating the necessary mixing for emulsification to occur. The properties of the resulting emulsified phase depend on the interplay of flow, mixing and emulsification kinetics of the surfactant/oil/water system. Emulsification can be relatively quick. Direct visualization of the process and compositional gradients in three-dimensional pore space during flow requires imaging at few seconds time intervals.

In this study, a flow unit was integrated in a synchrotron beamline-based fast X-ray computed micro-tomography set-up. Non-destructive three-dimensional visualization of multi phase flow inside pore space at flow conditions became viable. An oil saturated rock sample was first flooded with water, followed by surfactant solution to mobilize any
\end{abstract}


remaining oil. The sample was continuously imaged during injection; the scans were made at time intervals of 7-60 s.

The presence of emulsified phase in addition to the oil and the aqueous phases required a more advanced image processing workflow compared to immiscible fluid systems. A newly developed image processing technique was adopted; the grey levels in the images were correlated with the local oil content in the emulsified regions. The visual extractions of the pore space showed that emulsification occurred within seconds. Compositional gradients were observed in the emulsified phase as the injected surfactant solution reached remote locations in the pore space. While a significant fraction of the oil was displaced within few seconds, compositional gradients persisted over several millimeter length for several minutes, illustrating a sequence of mobilization and solubilization of the oil phase. The ability to interpret compositional gradients in real time in porous space brings capability to study interfacial phenomena in applications where in situ emulsification occurs under flow.

Keywords: micro-tomography, miscible displacement, surfactant, phase behaviour, flow cell

\section{Introduction}

Fundamental understanding of flow through porous media has considerably improved with advancing imaging techniques such as synchrotron beamline based fast X-ray computed micro-tomography (micro-CT). Direct imaging of pore scale processes at their natural length and time scale became possible [1-8]. The possibility of non-destructive imaging of three-dimensional rock specimens and the residing fluid phases offers research opportunities in disciplines like mineralogy, rock mechanics, reservoir characterization, and paleontology $[2,5,9-11]$.

By fitting a flow unit in the working space of micro-CT systems, multi-phase flow and displacement have been imaged in real-time in real rock samples [13-15]. Studies using 
model fluid systems have led to tremendous improvement in further understanding of multiphase displacement physics and imaging techniques. Immiscible two-phase fluid systems can be represented by two model fluids, i.e. water and n-decane, one of which is doped using an X-ray contrast agent. For sufficient doping levels, the grey level histograms show distinct regions for the solid and immiscible fluids such that the phases can be identified by separating the grey levels. This separation benefits from extensive research on systems where bimodal grey levels were binarized with modern segmentation methods to identify fluid connectivity [3] and non-wetting phase clusters and role of interfacial tension (IFT) in multi-phase displacement $[13,14,16]$.

However, most fluid systems relevant for applications like food processing or petroleum engineering are more complex. The complexity comes not only from their composition but also their influence on the wetting properties of the solid. For example, in petroleum engineering applications, crude oil resides in rock formations over many geological times and alters the wetting properties of rock surface affecting the fluid distribution. Unlike a model fluid, crude oil contains many impurities. Furthermore, when flowing simultaneously with an aqueous phase, crude oil can emulsify which can lead to compositional gradients [17-19]. Therefore, in micro-CT images of crude oils in rock samples, often a continuous grey level histogram is observed instead of a bimodal distribution as observed in model systems [20].

There are industrial applications where emulsification of the oil phase is generated intentionally. For example, surfactants can be used to enhance the recovery factor of oil production in oil reservoirs. Surfactants that can emulsify oil phase and form microemulsions are used as the displacement efficiency improves when the fluids become quasi-miscible [21]. Understanding the phase behavior oil/water/surfactant systems is, therefore, important because microemulsions has the ability to generate ultralow interfacial tensions (IFT) $\left(<1 \times 10^{-2} \mathrm{~m} \cdot \mathrm{Nm}^{-1}\right)$ that is required for miscibility to occur. Many studies focus on microemulsion formation and the resulting properties under equilibrium 
conditions. However, the majority of applications where microemulsions are present also involve flow. It is commonly assumed that the characteristics of an surfactant/oil/water system under flowing conditions are identical to the one under equilibrium conditions [22, 23]. The validity of this assumption was investigated in a microfluidic setup. The oil phase was coloured with a fluorescent dye, Nile Red, which allowed the visualization of multiple phases under fluorescent light. It was demonstrated that the emulsification kinetics were coupled to the pore-scale flow regime. Therefore, properties of properties of the microemulsions that form under flow conditions cannot be predicted solely from the static phase behaviour studies. However, the static phase behaviour studies can provide an indication at which concentrations of surfactant, oil and water the emulsification are likely to occur under flow.

The micromodel studies allowed to study mixing and emulsification in idealized geometries with limited connectivity. However, one would expect different flow and mixing behaviour in three-dimensional porous medium compared to those in twodimensional micromodels. For instance, due to high connectivity in three-dimensional porous geometries, the percolation threshold is lower than in two-dimensional [24]. This means that in three-dimensional geometries, for the injected wetting phase (i.e., aqueous phase) it is easier to bypass the non-wetting phase (i.e. oleic phase) trapped in the pore space.

Often, it is not intuitive how to project the observations made in two-dimensional to threedimensional in a quantitative way. The question of 'what really happens in threedimensional rock at the pore scale during emulsification' is still open. In this study, this question has been addressed by using fast X-ray computed micro-CT for real-time imaging of fluid distribution in a sandstone rock sample. The micro-CT set-up was fitted with a flow unit; the oil phase was doped to create a visual contrast between the oil and aqueous phases. The rock sample was initially oil saturated and was flooded with water until no more oil was produced. Following the waterflood, a surfactant solution was injected in the 
sample to mobilize the remaining oil that was trapped due to capillary forces. Because the surfactant emulsified the oil, in-situ emulsification occurred, and a third phase formed in the pore space.

The fluid distribution in the rock sample was imaged during the injections of water and surfactant solution. Time sequences of three-dimensional images were extracted and studied. This study provides a unique dataset to answer both the imaging and the flow phenomena related questions:

- Is it possible to image the formation of a third phase due to emulsification?

- How and where does the emulsification take place in porous media and how is the oil mobilized?

- Is the emulsification uniform everywhere in the pore space or is there a composition gradient in the emulsified phase?

\section{Materials and methods}

\section{Porous media}

Gildehauser sandstone from the Bentheimer formation was chosen because it is a relatively well characterized outcrop rock. The minerology and basic sample properties are listed in Table 1 and Table 2, respectively. The rock sample mainly consisted of quartz and some kaolinite clay. The pore size distribution was obtained by Hg-porosimetry; average pore size was 35 micrometers.

Table 1 Minerology of the Gildehauser rock sample.

\begin{tabular}{c|c|c|c|c} 
Illite \& mica & kaolinite & quartz & K feldspar & plagioclase \\
\hline trace & $2 \%$ & $94 \%$ & $3 \%$ & $1 \%$ \\
\hline
\end{tabular}

Table 2 Core sample properties.

\begin{tabular}{c|c|c|c|c} 
Rock & Porosity & Air Permeability & Core length & Core diameter \\
\hline Gildehauser sandstone & 0.2 & 1 Darcy & $20 \mathrm{~mm}$ & $4 \mathrm{~mm}$ \\
\hline
\end{tabular}




\section{Fluids}

Brine and oil were used as the immiscible model fluid pair. The brine composition is given in Table 3; the ionic composition prevented swelling and de-flocculation of the clays in the sandstone sample. The oil was n-decane doped with iodo-decane (20\% iodo-decane / 80\% n-decane) to enhance the X-ray contrast between the aqueous and oleic phases. The high amount of contrast agent was necessary to image the emulsified phase in which the contrast agent became diluted due to mixing with the surfactant solution. Prior to the coreflood, the sample was saturated with brine and was then drained by fast flooding with the oil phase to an initial water saturation of about $42 \%\left(\mathrm{~S}_{\mathrm{wr}}\right)$. The sample was embedded into polycarbonate by heat-shrinking before mounting into the flow set-up [18].

Table 3 Brine composition.

\begin{tabular}{c|c|c|c|c|c} 
Ion & $\mathrm{Na}^{+}$ & $\mathrm{K}^{+}$ & $\mathrm{Mg}^{2+}$ & $\mathrm{Ca}^{2+}$ & $\mathrm{Cl}^{-}$ \\
\hline$[\mathbf{m g} / \mathbf{L}]$ & 4270 & 7240 & 20 & 300 & 13750 \\
\hline
\end{tabular}

\section{Oil/surfactant/water system and static phase behavior}

The surfactant was an anionic, internal olefin sulfonate (IOS) with 20-24 carbon atoms (C20-24) and is manufactured by Shell Chemicals as the ENORDET® O Series [25]. The surfactant was chosen based on its capability to form microemulsions with n-decane at ambient temperature conditions. The surfactant solution was prepared by mixing $2 \%$ surfactant, $1 \% \mathrm{Na}_{2} \mathrm{CO}_{3}$, and 5\% 2-butanol (co-solvent) in water. All concentration values are given in weight-to-weight $(\% \mathrm{w} / \mathrm{w})$ ratio.

For the static phase behavior tests, bulk solution of surfactant was prepared. The phase behavior of the surfactant/oil/water system was studied as a function of salinity. In separate $10 \mathrm{~mL}$ test tubes $\left(\mathrm{V}_{\text {total }}\right), 5 \mathrm{~mL}$ surfactant solution was added $\left(\mathrm{V}_{\mathrm{w}}\right)$. The salinity of the solution was changed by adding different amounts of sodium chloride $(\mathrm{NaCl})$ in each tube 
mixture. Then $5 \mathrm{~mL}$ of $\mathrm{n}$-decane was added in each tube (mixing ratio of 1:1). The contents of the tubes were shaken vigorously, and the tubes were allowed to rest as the phases separated under the influence of gravity. Once equilibrated, the microemulsion phase formed an opaque middle layer that contained most of the surfactant and some water and oil as shown in Figure 1.

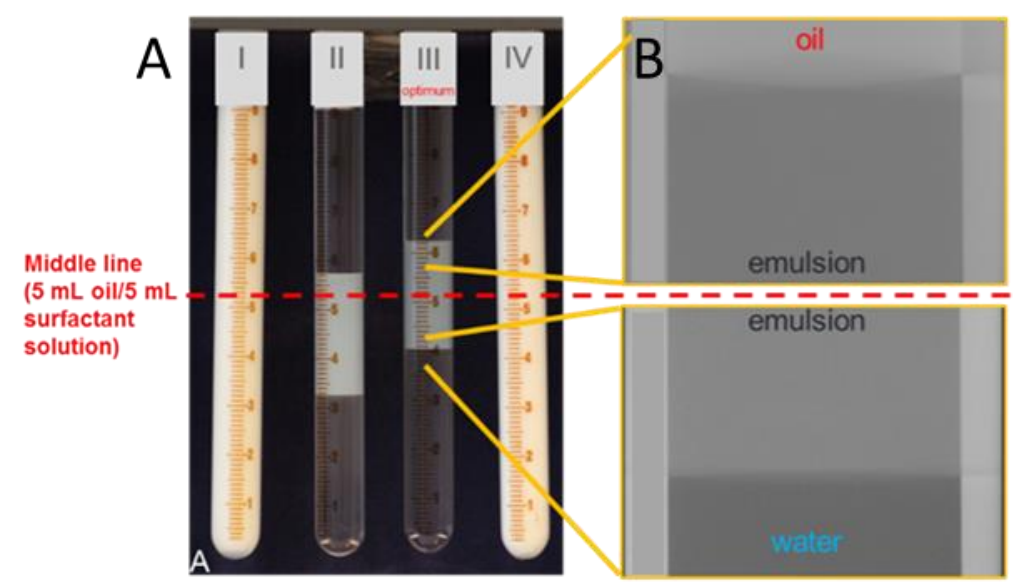

Figure 1 (A) Salinity scan of surfactant/oil/water system, B) micro-CT X-ray scan of optimum salinity Tube III.

Table 4 Fluid properties of middle phase emulsions at different salinities. IFT values were measured using spinning drop method and was between microemulsion phase and aqueous phase [22]. * due to inhomogeneous structure of the emulsion, it was not possible to obtain a stable value for the microemulsion phase viscosity in Tube I.

\begin{tabular}{l|c|c} 
& $\begin{array}{c}\text { Viscosity } \\
(\mathrm{mPa} . \mathrm{s})\end{array}$ & $\begin{array}{c}\mathrm{IFT} \\
\left(\mathrm{mN} . \mathrm{m}^{-1}\right)\end{array}$ \\
\hline Tube I (micro)emulsion & $\sim 20^{*}$ & $1 \times 10^{-2}$ \\
\hline Tube II (micro)emulsion & 5 & $1 \times 10^{-2}$ \\
\hline Tube III (micro)emulsion & 4 & $2 \times 10^{-3}$ \\
\hline Tube VI (micro)emulsion & 6 & $1 \times 10^{-2}$ \\
\hline Brine / surfactant solution & 1 & - \\
\hline n-decane & 0.85 & - \\
\hline
\end{tabular}


The optimum salinity was determined based on the hydrophilic-lipophilic deviation (HLD) theory that formulates an equivalent dimensionless expression for systems containing surfactants, electrolytes, co-surfactants, oil etc. [26-29]. If HLD $=0$, the surfactant exhibits similar affinity for the aqueous and oil phase, therefore the forming microemulsion contains equal volumes of the aqueous and oil phases. If HLD $>0$ the surfactant exhibits more affinity for the oil, and if HLD $<0$ the affinity is more favorable for aqueous phase. Changing the formulation variables, e.g. salinity, oil type, surfactant type, and/or temperature, can vary the HLD.

The solubilization was analyzed via the oil and water solubility ratios, $\gamma_{w}$ or $\gamma_{0}$, into the microemulsion be determining (from the graded tubes) the volume of water, $\mathrm{V}_{\mathrm{w}}$, or oil, $\mathrm{V}_{\mathrm{o}}$, solubilized into the microemulsion phase per unit weight of surfactant. At the optimum salinity $(\mathrm{HLD}=0), \gamma_{\mathrm{w}}$ equals $\gamma_{\mathrm{o}}$. i.e., surfactant had similar affinity to water and oil phases. For the system studied here the optimum salinity was at $1.25 \% \mathrm{NaCl}$. The middle phase microemulsion phase in equilibrium with both excess oil and aqueous phases (Figure 1A, Tube III), and it contained 50\% surfactant solution and 50\% oil. At $0.75 \% \mathrm{NaCl}$ salinity (HLD $<0$ ), the lower phase microemulsion was in equilibrium with the excess oil whereas at high salinities (Figure 1A, Tube II). At $0.75 \% \mathrm{NaCl}$, there were no phase separation and only a single milky phase formed. The $1.5 \% \mathrm{NaCl}$ tube (Tube IV) content looked similar to the Tube I, however, at this salinity the salinity is overoptimum (HLD>0). Therefore, the single phase in Tube I is water-in-oil emulsion, while the content of Tube IV is most probably an oil-in-water emulsion. The IFT was measured using spinning drop method; at optimum salinity, the IFT between microemulsion phase and the aqueous phase was $2 \times 10^{-3} \mathrm{mN}^{-1}$. The IFT values at other salinities were also ultra-low (Table 4). The tubes were observed under normal light with naked eye; the middle phase formed within couple of minutes. There was no visible change in the phase boundaries, therefore, it was assumed that the microemulsion formation was completed. 
Since the oil was doped with iodo-decane, the phase behaviour tests were repeated with the n-decane doped with iodo-decane. The doping agent did not affect the phase behaviour of the surfactant/oil/water system; optimum salinity did not shift. Once equilibrated, the optimum salinity test tube $(1.25 \% \mathrm{NaCl}$, with doped n-decane) was scanned in a laboratorybased X-ray computed micro-tomography set-up (Zeiss Versa 520, Zeiss, Germany). The X-ray contrast between the (doped) oil and the aqueous phase in the middle microemulsion phase was analysed. The oil (top layer), aqueous (bottom layer) and the microemulsion (middle layer) phases had distinct grey values (Figure 1B). The aqueous and oil phase content of the microemulsion was estimated using the linear blending rule for X-ray attenuation coefficients expressed here as

Gray value $($ microemulsion $)=\beta_{\mathrm{o}} \times$ Gray value $($ oil $)+\beta_{\mathrm{w}} \times$ Gray value $($ water $)$

where oil and water content of the emulsified phase are $\beta_{\mathrm{o}}$ and $\beta_{\mathrm{w}}$, respectively.

Based on this analysis, the oil and water content of the optimum salinity microemulsion (middle) phase was determined as 0.53 and 0.47 , respectively. These values are indicative of the phase behavior at optimum salinity conditions: approximately equal volumes of water and oil were solubilized in the microemulsion phase at optimum salinity $(\mathrm{HLD}=0)$.

\section{Emulsification under flow conditions}

During the surfactant flooding, the local concentrations of surfactant solution, oil and water in the pore space continuously change due to flow. The fluid system is dynamic, and it is unlikely that there will be an equilibrium. Note that, in the static phase behaviour tests, several minutes are required for the surfactant/oil/water system to reach equilibrium and form the microemulsion (Figure 1). Instead, there will be a gradient of composition during the flow; emulsified phase, injected surfactant solution and mobilized oil will flow simultaneously and mix. While microemulsion formation will still occur, it is unlikely that their composition and properties will be the same as the microemulsions that form at static 
(equilibrated) conditions (Figure 1). It is possible that the microemulsions that form in stagnant zone, where flow is minimal, will have similar properties to the ones shown in Figure 1 (considering the same concentrations of surfactant solution, oil and water will be present).

In the current experiment, because the local concentrations of oil and surfactant solution continuously changed in the flow experiments, the composition and properties of the emulsified phase also changed. It is also possible that, in some regions of the pore space, the relative concentration of the surfactant was low and the IFT did not even reduce to ultra-low values to form a miscible system. Alternatively, some regions benefitted from relatively high flow of surfactant solution and most oil was emulsified.

Due to ever-changing compositional gradients in the pore space, the images taken during the micro-CT experiment were used to quantify the relative changes in local oil saturations in the pore space. The image analysis technique was used to correlate the changes in the oil saturations with and emulsification rates. The technique was improvised to distinguish between the emulsified and non-emulsified oil in the images. However, the technique cannot identify which regions have kinetically equilibrated or unequilibrated microemulsions and/or emulsions.

In the following discussions, microemulsion formation will be referred to as emulsification and any phase that forms as a result of the emulsification will be referred to as the 'emulsified phase'. The terms of 'microemulsion' and 'emulsion' are avoided as it is not possible to know the properties of the emulsified phases.

\section{Beamline based fast micro-CT flow experiments}

The flow experiments were performed using the synchrotron beamline-based fast X-ray computed micro-CT at the TOMCAT beamline of the Swiss Light Source (Paul Scherrer Institute, Switzerland). The changes in fluid distribution in three-dimensional pore space 
of the rock was monitored during the initial waterflood and a subsequent injection of surfactant solution. The rock sample was first embedded into polycarbonate sleeve by heatshrinking and was mounted vertically in the flow setup. Two remotely controlled piston pumps were used for injection of fluids [30]; the remote connection enabled continuous rotation for tomography. The injection was done from the bottom of the sample. The injection rate was $30 \mu \mathrm{l} \cdot \mathrm{min}^{-1}$ for both injection sequences and corresponded to an interstitial velocity of approximately $12 \mathrm{~mm} \cdot \mathrm{min}^{-1}$ or 0.57 pore volume (PV) per minute.

A velocity of $12 \mathrm{~mm} \cdot \mathrm{min}^{-1}$ corresponds to approximately $50 \mathrm{ft}^{-d a y}{ }^{-1}$. In hydrocarbon recovery applications, the commonly accepted fluid velocity in the reservoir (far from the wellbore) is $1 \mathrm{ft} . d a y^{-1}$. A velocity of $50{\mathrm{ft} . d a y^{-1}}^{-1}$ could be representative velocity near the wellbore region where the velocities are significantly higher. The injected surfactant solution would contact the oil phase and form the high-viscosity emulsified phase at the oil/water contact. This emulsified phase would push the oil ahead forming a clean oil bank.

The field of view was $4 \mathrm{~mm}$ wide and $4 \mathrm{~mm}$ high and was located $2 \mathrm{~mm}$ above the inlet (Figure 2). A white beam with 5\%, 250 um Al was used. During the flow experiments, for each three-dimensional image 1500 projections over 180 degrees rotation were taken. The images obtained from the beamline were reconstructed using the Paganin method [31, 32]. The resulting in three-dimensional images of $1400 \times 1400 \times 900$ voxels with resolution of 3.0 $\mu \mathrm{m} / \mathrm{voxel}$. The resolution field of view combination chosen was the best compromise between resolving spatial features like compositional gradients and covering a Representative Elementary Volume (REV) of the porous medium of interest. 


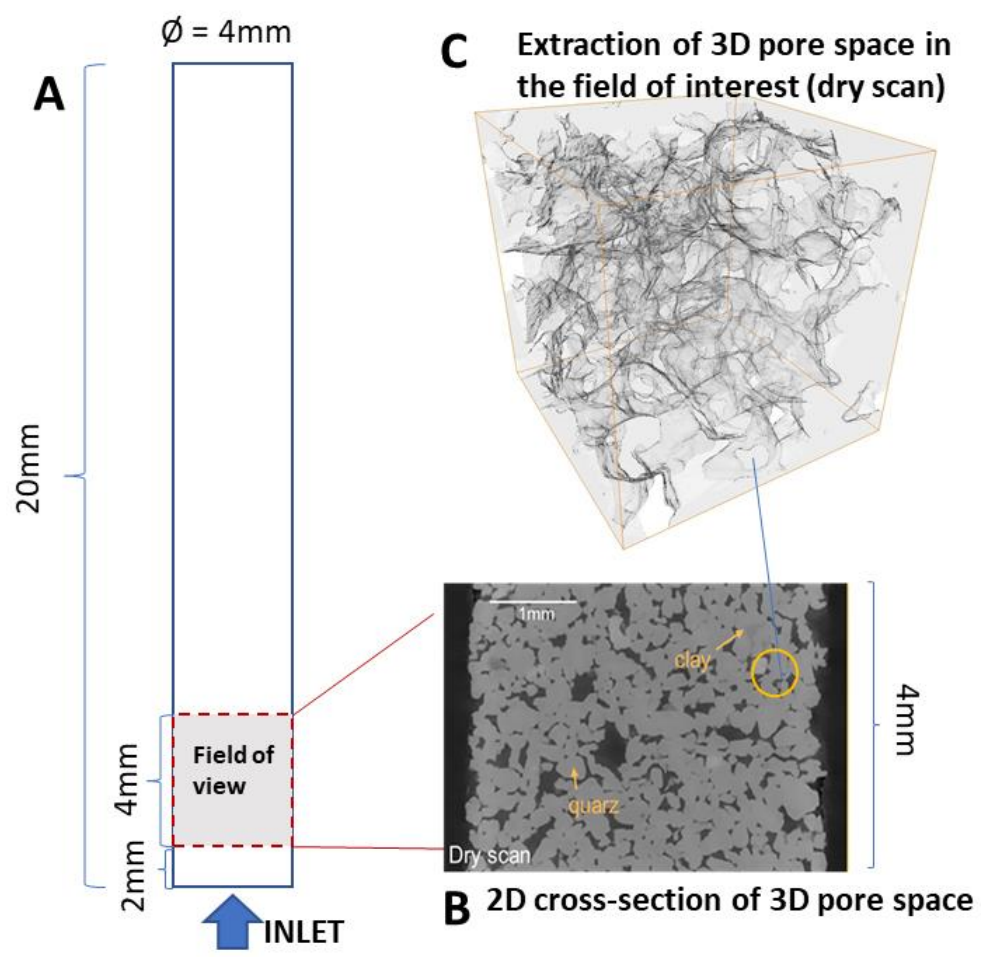

Figure 2 A) Sketch of core sample (diameter $=4 \mathrm{~mm}$, height $=20 \mathrm{~mm}$ ). Field of view is $4 \mathrm{~mm}$ section, B) a vertical cross-section from three-dimensional pore space. Dry scan of the sandstone rock showing pore space (black) and grains (grey), C) three-dimensional pore visualization of field of interest.

The image acquisition was completed in $7 \mathrm{~s}$ which was the time required for a full threedimensional scan with 1500 projections. Individual pore scale displacement events, such as Haines jumps and snap-offs, take milliseconds to complete, but they repeat at time intervals greater than $7 \mathrm{~s}[3,33,34]$. This way, during $7 \mathrm{~s}$ acquisitions, for most of the threedimensional scans the fluid interfaces were at rest. Only occasionally pore scale displacement events took place during the acquisition of a three-dimensional scan. These events caused artifacts in the reconstruction such as blurring and intermediate grey levels $[33,35]$. This is also known as partial volume effects (see Supporting Material section).

Imaging of the waterflood was performed at initially $7 \mathrm{~s}$ and later $1 \mathrm{~min}$ time intervals. Evolution of the immiscible displacement of oil by the injected water was visualized through a sequence of images establishing a static configuration of the oil remaining at the end of the waterflood. The scan rate for the surfactant flooding was initially $7 \mathrm{~s}$ for the first 
$3 \mathrm{PV}$ of injection. Afterwards, the scan interval was extended to 1 minute to cover a longer time interval with potentially slower processes, i.e. diffusive processes.

Note that the scintillator (converting X-ray photons into visible light which is then recorded by the CCD camera) showed slightly different grey levels during $7 \mathrm{~s}$ and 1 min scan intervals. During the $7 \mathrm{~s}$ scan intervals, the scintillator was continuously exposed to X-ray radiation. At the $1 \mathrm{~min}$ intervals, the initial exposure time was also $7 \mathrm{~s}$ followed by a $53 \mathrm{~s}$ period without exposure which resulted in slight shift in average grey levels.

Once the surfactant flood was completed, the sample was flushed with iso-propanol until it was free of any emulsified phase, oil and surfactant solution. The cleaned sample was dried and scanned (dry scan, Figure 2B) to segment the pore space without any fluid. The dry scan was taken at longer integration time ( $70 \mathrm{~s}$, ten times of integration time used for the flow scans) to segment the pore space more accurately.

\section{Image processing}

Reconstructed three-dimensional volumes were first registered on the dry scan, and then were filtered using 'nonlocal means' approach [36, 37]. Further image processing was done using Avizo 9.0 (Thermo Fisher Scientific, USA) and Matlab (MathWorks, USA) [30]. The interpretation of the scans in terms of saturations of water, oil and emulsified phases followed a four-step workflow:

Step 1 - Dry scan segmentation: Pore space and grains were segmented (binarized) on the dry scan (Figure 2B). This was possible because pore space and grains could be clearly distinguished in the histogram without any liquid in the pore space. 
Step 2 - Segmentation of waterflood scans: the dry scan segmentation was projected over the waterflood scans. The grains were masked using the segmented dry scan; only the pore space remained for further analysis.

It would be intuitive to expect a specific grey value for water and another one for oil phase. However, instead of two single peaks, a range of grey values were detected during the waterflood. A grey level histogram was plotted which showed a bimodal distribution in the fluid range (Figure 3A). This is common in micro-CT experimentation where multiple phases are involved and it is due to beam-hardening artefacts and partial volume effects at the edges. Using the watershed segmentation method, the fluid compositions were segmented in the pore space using the peak values in the histograms as seed points [38, 39] (See Supporting Material section).

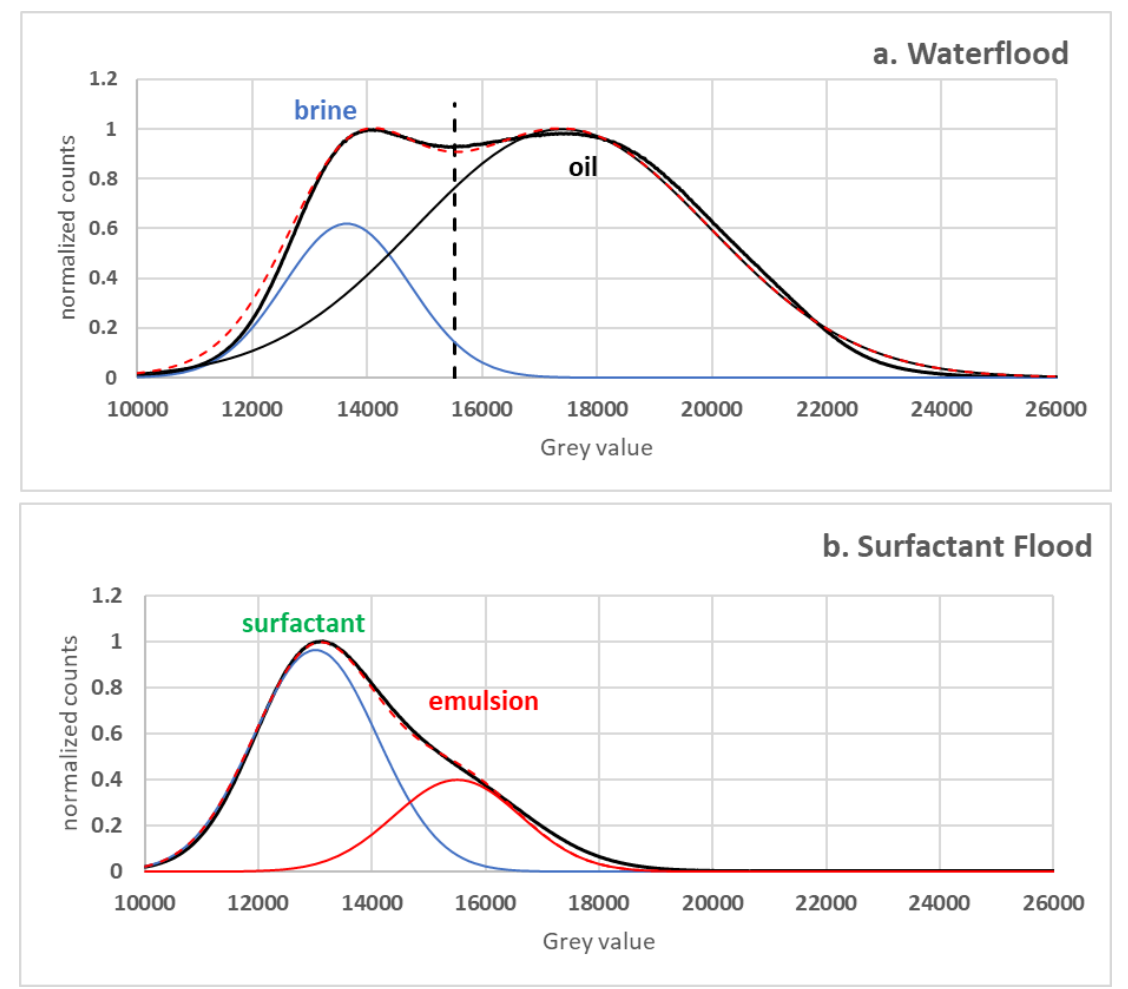

Figure 3 Grey level histogram of the pore space for the waterflood (a) and the surfactant flood (b). 
Step 3 - Interpretation of oil saturation via mean grey values in the pore space: Saturation of oil and water phases could be obtained from segmenting the images as described in Step 1 and 2. However, when emulsified phases were present (during the surfactant flood), an alternative strategy became necessary. The interpretation was performed based on the average grey level in the pore space. In images where all three phases were present, composition of the emulsified phase could be estimated using Equation 1. In the time sequence of the surfactant flood, however, the oil phase was immediately emulsified. Due to systematic errors related to the dopant in the oil-phase, the peak grey values obtained during the waterflood could not be used directly to estimate the oil content in the emulsified. Instead the oil content of the emulsified was estimated based on a correlation between the mean grey values and saturations obtained from the waterflood.

Mean grey levels in pore space during waterflood were computed (Steps 1-2). For improved signal-to-noise ratio, volume averaged grey levels were considered. The grey level values in individual waterflood scans were averaged over whole cross sections spanning over many pores (no grains). Since the pore space was well defined at the dry scan segmentation (step 1), it was possible to segment the water and oil saturations explicitly in individual pores. Consequently, one could derive the oil saturations from the images. The correlation between the oil saturation and average grey values was derived; a linear correlation was observed (Figure 4). 


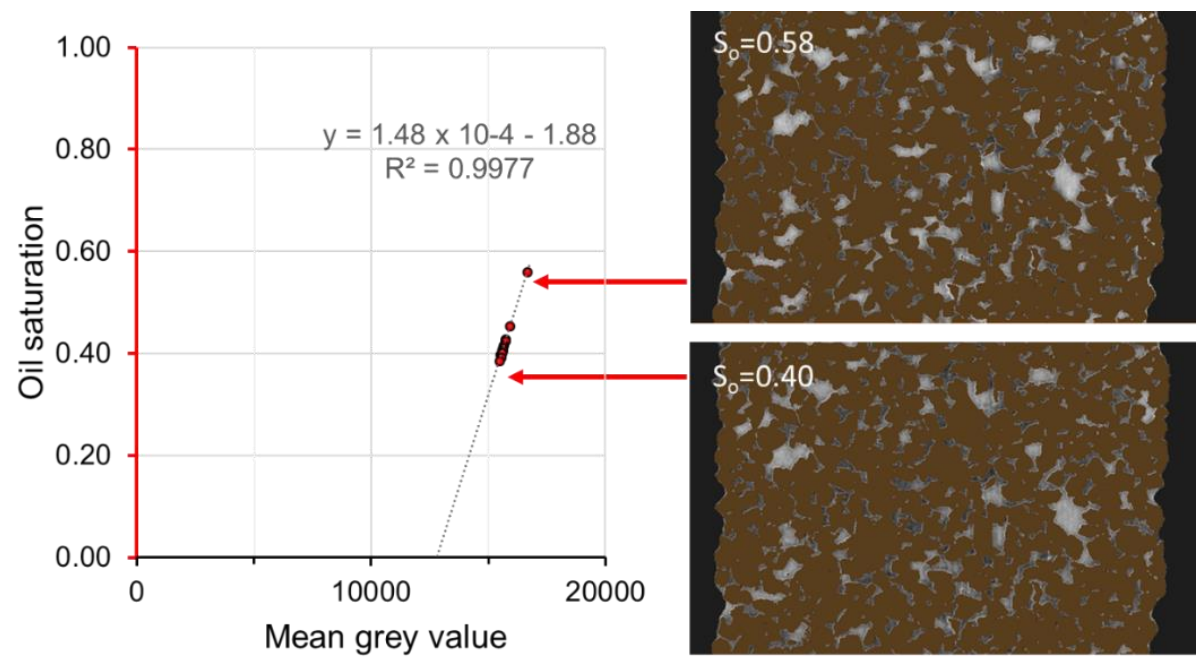

Figure 4 Calibration of average oil saturation vs. grey level in the micro-CT images during waterflood. A correlation was derived and was also used for processing the images of the surfactant flood.

Step 4 - Interpretation of the surfactant flood: Due to emulsification, no obvious interface was visible between oil and water phases. Furthermore, there was a gradient in the emulsification levels. The linear correlation derived in Step 3 was used to interpolate the grey levels associated with the degree of emulsification. Average grey values were also determined in the surfactant flood scans. Using the linear correlation from the waterflood scans, corresponding oil saturations were determined in the pore space.

\section{Results and Discussion}

\section{Changes in average oil saturation}

All scans taken during the waterflood and surfactant flood were processed to determine the average oil fraction in the field of view (Figure 2). The oil saturation as a function of time for the waterflood and the surfactant flood is displayed Figure 5. During the waterflood, the oil saturation reduced from $S_{o i}=0.58$ to $S_{o}=0.39$ due to immiscible displacement (Figure 5a). The non-monotonic behavior around $t=5 \mathrm{~min}$ is not attributed any change in oil saturation. It was caused by the change in scan intervals from $7 \mathrm{~s}$ to 1 min leading to a slightly different response of the scintillator. It was not possible to remove the artifact by e.g. a calibration in a reliable way, therefore, it was decided to display uncorrected data. 

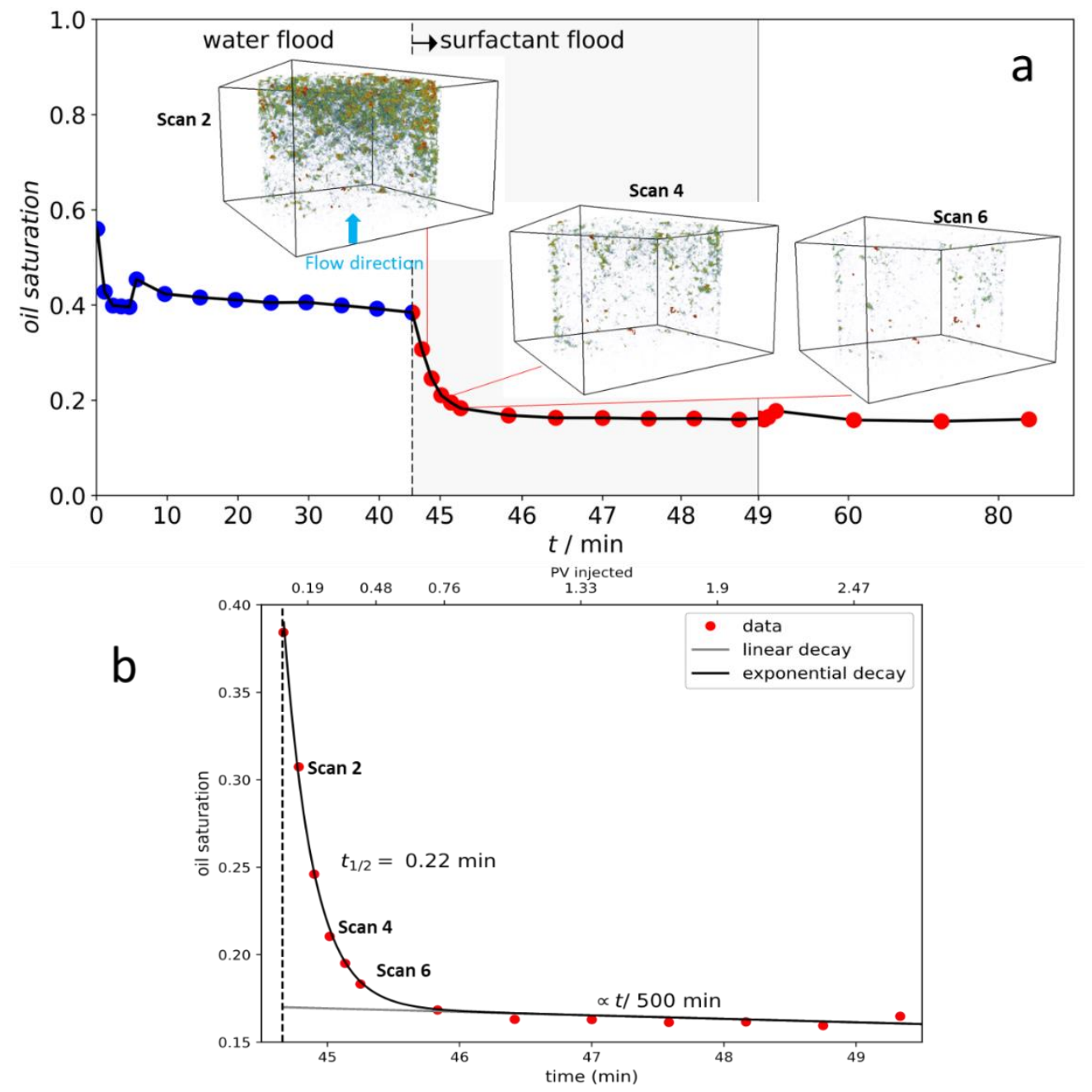

Figure 5 a) Volume averaged oil saturation as a function of time during the waterflood and the surfactant flood. stretched (logarithmic) time interval during the first minute of surfactant injection shows a steep decrease in oil saturation in less than 1 PV indicative for a mobilization mechanism. b) Two regimes observed in the oil saturation decay.

Two distinct regimes were identified in the oil saturation decay (Figure 5b). In the first regime, there was a quick drop in oil saturation from $S_{o}=0.39$ to $S_{o}=0.18$ in $1 \mathrm{~min}$ and with less than $1 \mathrm{PV}$ injection. The oil saturation profile during first regime was fitted with an exponential curve with an exponent of $t_{1 / 2}=0.22 \mathrm{~min}$ (Figure $5 \mathrm{~b}$ ). The oil that was mobilized during this time was within relatively easy reach of the injected surfactant solution. Reduced IFT would lower the capillary pressures between the aqueous solution 
and oil phases. As a result, the surfactant solution would gain easier access to pore space which was not reached during the waterflood. Some of this 'easy' oil was swept and some of it would be emulsified and carried away by the surfactant solution. Two displacement mechanisms were believed to be responsible for the oil displacement during this time, 1) oil being swept due to convective flow, and 2) emulsification. In an earlier microfluidic study [20], these two mechanisms were studied in detail (see Supporting Material for 'Time Scales of Emulsification").

In the second regime, oil saturation almost stabilized at $S_{o}=0.18$, and very slowly dropped to $S_{o}=0.16$ over the following 5 minutes (Figure $5 b$ ). Once the 'easy' oil was mobilized during the exponential regime, the surfactant solution continued to penetrate deep into the pore space that was far away from the main flow channels, i.e. dead-end pores, disconnected oil clusters. In the absence of convective flow, the mobilization mainly relies on diffusive processes which can be very slow.

Due to ongoing injection, the surfactant/oil/water system would not reach equilibrium and the local compositions would continuously change. It is likely that the IFT values were reduced but never became ultra-low (i.e. $1 \times 10^{-3} \mathrm{mN}^{-1}$ ) during the surfactant flood. The surfactant solution was injected at optimum salinity; however, it would probably never form optimum microemulsions during the flow. The emulsified oil phase probably had under- or over-optimum composition (see Oil/surfactant/water system and static phase behavior section). Note that, the viscosity of the emulsified phase would also be significantly higher that the viscosity of the oil and the aqueous solution (Table 4). Therefore, the mobility of the emulsified oil would be less than non-emulsified oil.

\section{Grey level histograms}

The respective grey level histograms of the waterflood (start and end of waterflood) and surfactant flood (scans 1, 2,7) are displayed in Figure 6. The waterflood histograms showed a bimodal distribution; one peak for brine and another one for the oil (Figure 6, 
black and yellow lines). This was typical for an immiscible system. Compared to histogram at the beginning of the waterflood, the histogram at the end of the waterflood shifted towards lower grey values and had a higher brine peak (Figure 6, compare black and yellow lines); the oil peak was less pronounced. This was in agreement with the increased water saturation in the core.

The grey level histograms of the surfactant flood had left-skewed monomodal distribution. Two of the histograms shown in Figure 6 belongs to the scans where there was an exponential decay in the oil saturation (Figure 5). Already in the first scan of the surfactant flood (taken at 7s surfactant injection), the bimodal distribution of the waterflood scans was not observed (red line). There was no clear distinction between oil and water in terms of grey values. This is a characteristic profile for an emulsified phase; it also meant that the oil remaining after the waterflood was almost immediately emulsified.

During the exponential decay of the oil saturation (Figure 5b, data points for scans 1- 2), one can see a further shift of the peak of the histogram to lower grey levels (Figure 6). This meant that the oil fraction was further decreasing. Later in the process, when the decrease in oil saturation levelled off (Figure 5b, scan 6), the histogram still had a finite count in the grey level (Figure 6, blue line extends to grey values of $>18,000$ ) indicating that there was a fraction of non-emulsified oil remained in the pore space. 


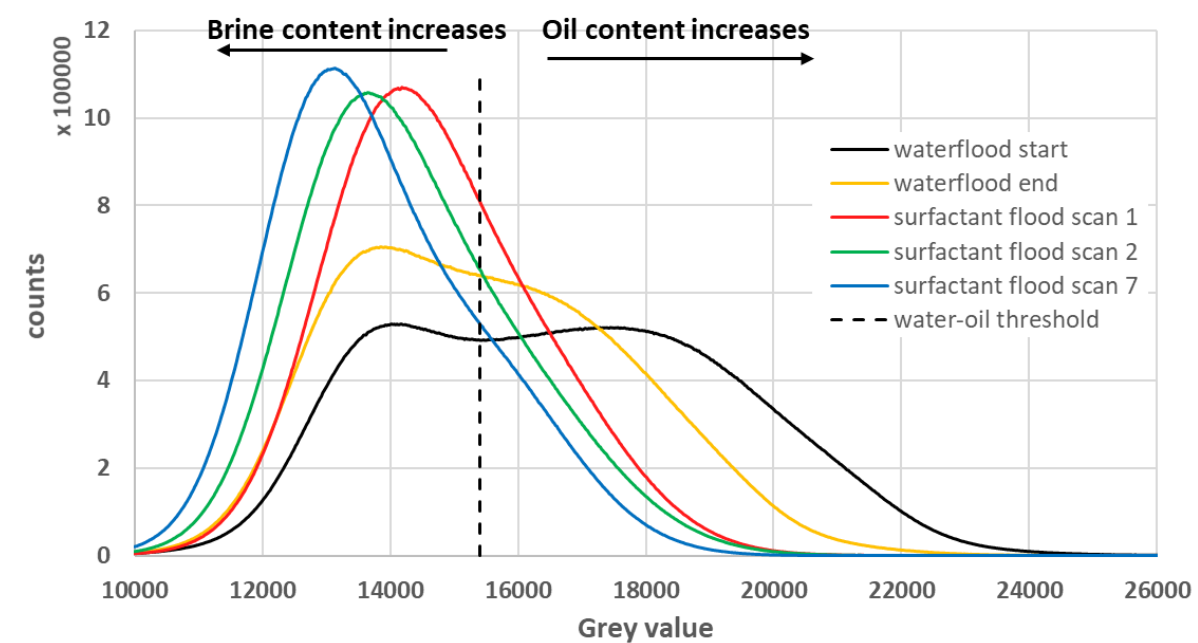

Figure 6 Grey level histograms for the first and last scan of the waterflood, and scans 1, 2, and 7 of the surfactant flood (Figure 5).

\section{Three-dimensional visualization of waterflood scans}

The waterflood scans were further analyzed to study local displacement mechanisms in three-dimensional pore space. Field of interests (FOI) were identified and were zoomed into the three-dimensional extractions of the waterflood. Figure 7 shows the remaining oil phase distribution over 1.5 min of water injection. Red color represents the oil phase; water phase is rendered transparent for better visibility of the pore space. A FOI was selected at the front top corner (Figure 7, blue square). The close-ups of the FOI revealed the typical characteristics of the immiscible displacement of oil by the water. At $t=1.08 \mathrm{~min}$, there was a cluster of oil phase that was spanned over multiple pores. At time $t=1.28 \mathrm{~min}$, some of the oil was mobilized and the remaining oil was broken into smaller disconnected clusters by snap-off processes [40]. The smaller clusters then became increasingly trapped by capillary forces. 


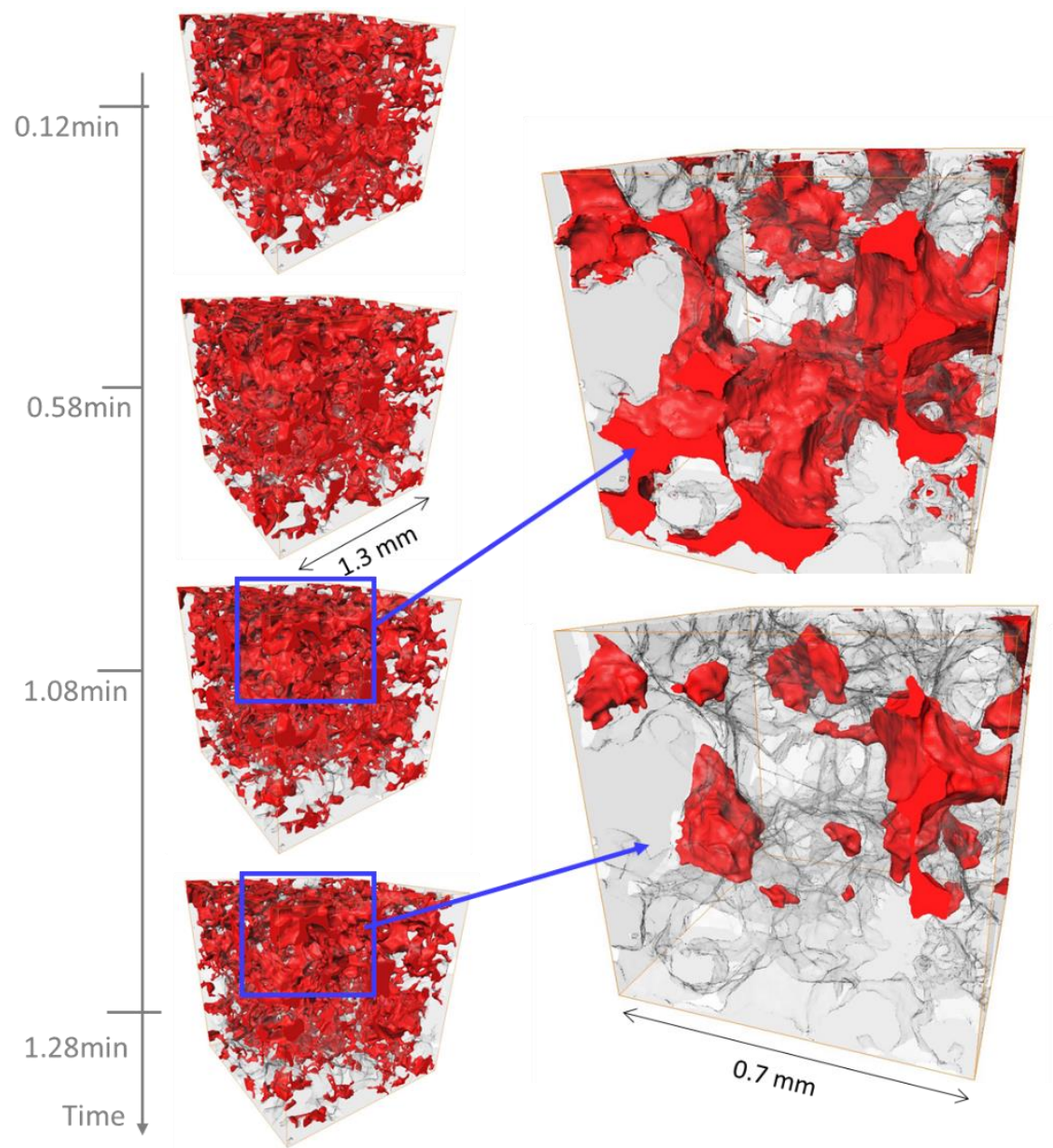

Figure 7 Sequence of oil phase distribution in three-dimensional pore space over 1.3 min of water injection.

\section{Three-dimensional visualization of surfactant flood scans}

Scans of the surfactant flood were examined for local displacement events where the oil displacement by emulsification was observed. Two FOI were chosen where there was an exponential decay in oil saturation (Figure 8, red (A) and blue (B) circles). A third FOI was identified where the decay in the oil saturation was in the linear regime (Figure 8, black circle $(\mathrm{C})$ ). In green circle (E) in the scan 6, some emulsified phase appeared (Figure 9, dashed green circle). This emulsified phase may have newly formed due to 
emulsification of trapped oil. Alternatively, some emulsified phase may have migrated from other parts of the rock.

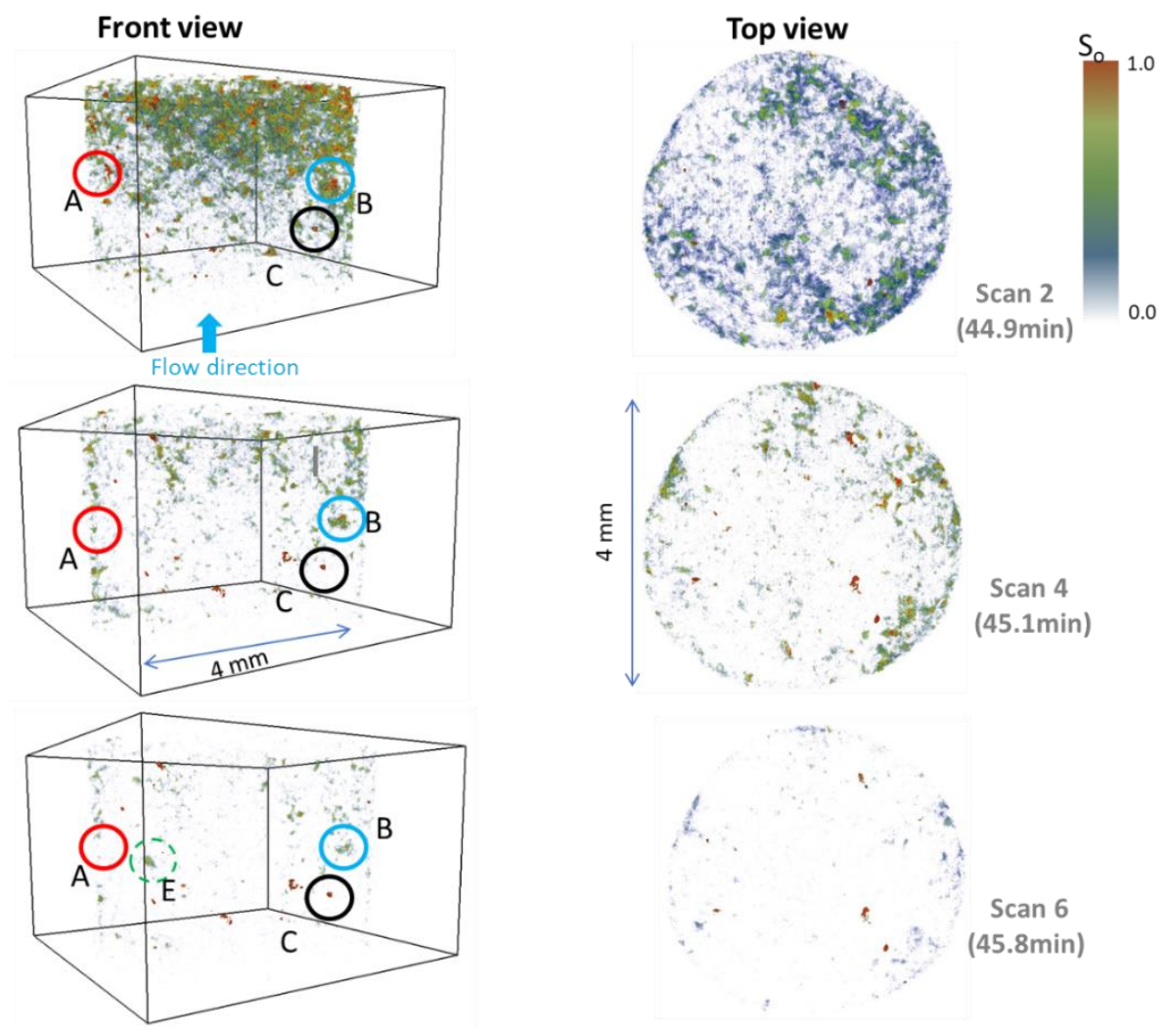

Figure 8 Scans of field of view during surfactant flood. Top row is the front view; three FOIs are marked (red, blue and black circles). Bottom row is the view from the top.

Close-ups of the three ROIs (A, B, C) for surfactant flooding are shown in Figure 9. The ' $\mathrm{A}$ ' region shows two oil clusters: one is located at the middle left and the other is on the top right corner of the section (Figure 9, top row). At $t=44.9 \mathrm{~min}$, there was a gradient in oil saturation in both locations. The oil saturation was higher in the center (red) and it gradually decreased towards outside. It suggested that the surfactant solution emulsified some oil. After just a few seconds $(t=45.1 \mathrm{~min})$, the oil cluster on the left was significantly reduced in size. The red center disappeared, and a smaller blue phase remained (blue color suggested lower oil content in the emulsified phase). The oil cluster 
on the right was fully solubilized except for a few blue spots. $7 \mathrm{~s}$ later, both clusters were almost invisible.

In the ' $\mathrm{B}$ ' region, there was initially a large cluster of oil in the center (red) surrounded by emulsified phase (green/blue) (Figure 9, middle row, $t=44.9 \mathrm{~min}$ ). The gradient in the color indicated different levels of emulsification. At $t=45.1 \mathrm{~min}$, the oil cluster significantly reduced in size, and most of the red patches disappeared. 7 seconds later, the cluster showed a lower oil content in the emulsified phase (color turns from red to blue).

A
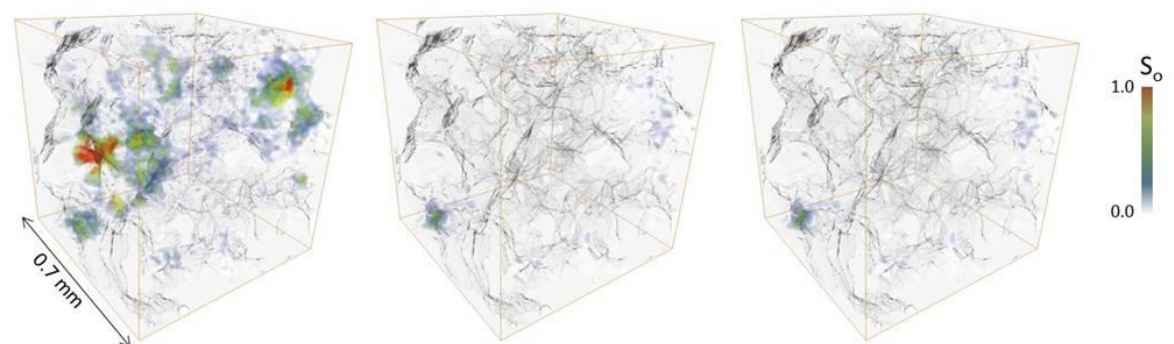

$B$
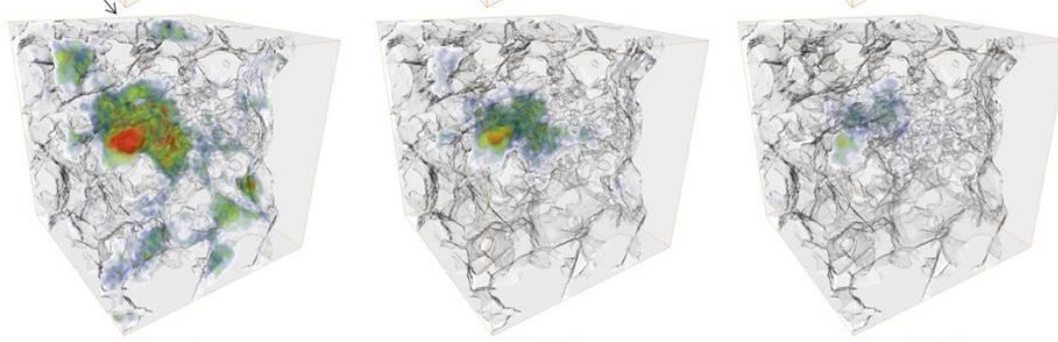

C.
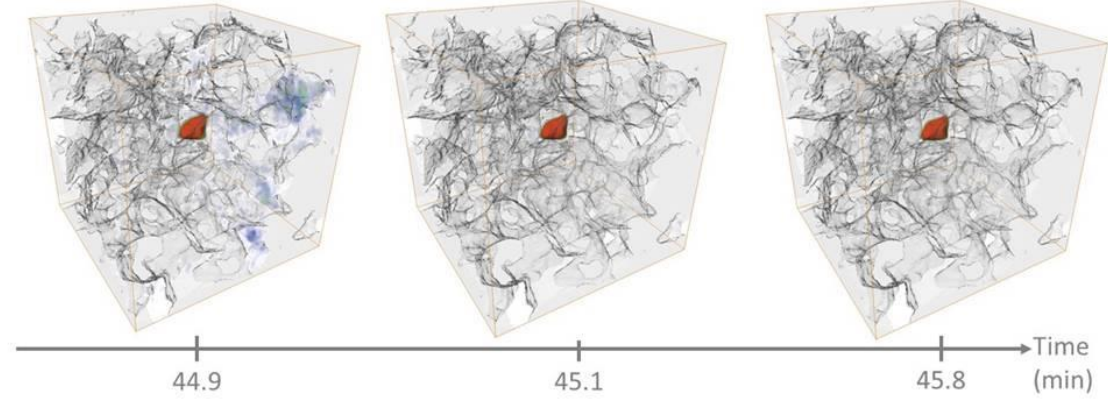

Figure 9 Close-ups of two FOI during surfactant flood for the fields of interest (FOI) A, B and C marked in Figure 8.

The bottom row of Figure 9 shows the ' $\mathrm{C}$ ' region where oil displacement was slower compared to 'A' and ' $\mathrm{B}$ ' regions. A disconnected oil cluster was monitored during the 
surfactant flooding. The red color suggested that the cluster consisted mainly of oil and there was hardly any emulsification. It is likely that this cluster was disconnected from the main flow path and the surfactant solution did not reach during the exponential decay regime in oil saturation. It is likely that this cluster was emulsified later when the decay in oil saturation was linear (Figure 5, $t>46 \mathrm{~min}$ ).

\section{CONCLUSION}

In the last decade, the X-ray tomography techniques have advanced to a level where threedimensional non-destructive imaging of time series with time resolutions of a few seconds has become possible. Respective imaging techniques has successfully been applied to immiscible two-phase flow systems in porous media [2-8, 13-15]. The systems studied so far consisted of distinct individual phases which can be separated for further interpretation by well established image segmentation methods [3].

However, most fluid systems in nature are complex; due to (partial) miscibility continuous compositional gradients occur. Imaging of such fluid systems is not possible using the traditional segmentation methods that are used for immiscible fluid systems. In this study, we developed a new image processing workflow that is based on grey level histograms. The compositional gradients in the emulsified phase were associated with the grey levels in the images which were then correlated to local oil content in the emulsified phase.

Using the rapidly advancing possibilities of X-ray computed tomography in terms of spatial and temporal resolution, combined with the novel image processing methodology, the next step would be to study in situ emulsification in other types of multi phase flow systems where miscibility occurs. A fluid system that utilizes phase contrast instead of attenuation contrast would make it possible to identify different phases without the contrast agent. Absence of a contrast agent would reduce the non-physical artefacts in the images and would improve the interpretation. The ability to interpret compositional gradients in real 
time in porous space brings capability to study interfacial phenomena in applications where in situ emulsification occurs under flow.

\section{ACKNOWLEDGEMENTS}

Authors acknowledge the Paul Scherrer Institute, Villigen, Switzerland for provision of synchrotron radiation beamtime at beamline TOMCAT of the SLS. They also thank F. Marone and M. Stampanoni for their support during experimentation. 


\section{REFERENCES}

1. M.E. Coles, R.D. Hazlett, E.L. Muegge, K.W. Jones, B. Andrews, B. Dowd, P. Siddons, A. Peskin, P. Spanne, W.E. Soll, Developments in synchrotron x-ray microtomography with applications to flow in porous media. SPE Res Eval \& Eng 1 (1998) 288-296.

2. V. Cnudde, M.N. Boone, High-resolution X-ray computed tomography in geosciences: a review of the current technology and applications, Earth Science Reviews, 13 (2013) 1-17. https://doi.org/10.1016/j.earscirev.2013.04.003

3. Schlüter, S.; Sheppard, A.; Brown, K.; Wildenschild, D. 2014. Image processing of multiphase images obtained via X-ray microtomography: a review. Water Resources Research, 50, 3615-3639.

4. D. Wildenschild, A. Sheppard, X-ray imaging and analysis techniques for quantifying pore-scale structure and processes in subsurface porous medium systems. Adv. Water Resources, 51 (2013) 217-246.

5. S. Berg, S. Oedai, D.W. van Batenburg, K. Elewaut, D.M. Boersma, E.M. Ineke, Visualization of ASP core flood experiments with X-ray CT imaging, EAGE 18th European Symposium on Improved Oil Recovery, paper B12, Dresden, 14-16 April 2015.

6. L. Zhang, M. Wang, Electro-osmosis in inhomogeneously charged microporous media by pore-scale modeling. Journal of Colloid and Interface Science, 486 (2017) 219-231.

7. H. Zhang, T.S. Ramakrishnan, A. Nikolov, D. Wasan, Enhanced oil displacement by nanofluid's structural disjoining pressure in model fractured porous media. Journal of Colloid and Interface Science, 511 (2018), 48-56.

8. T. Pak, N.L. Archilha, I.F. Mantovani, A.C. Moreira, I.B. Butler, The Dynamics of Nanoparticle-enhanced Fluid Displacement in Porous Media - A Pore-scale Study, Sci. Rep. 8 (2018). doi:10.1038/s41598-018-29569-2. 
9. D. Wildenschild, J.W. Hopmans, M.L. Rivers, A.J.R. Kent, Quantitative analysis of flow processes in a sand using synchrotron-based X-ray microtomography. Vadose Zone Journal, 4 (2005), 112-126.

10. Z.T. Karpyn,A.S. Grader, P.M. Halleck, Visualization of fluid occupancy in a rough fracture using micro-tomography. Journal of Colloid and Interface Science 307(1) (2007) 181-187.

11. J.J. Funk, E.M. Withjack, S. Siddiqui, S.M. Al-Enezi, S. Caliskan, Core imaging Twenty-five years of equipment, techniques, and applications of X-ray computed tomography (CT) for core analysis. Proceedings of the Society of Core Analysts SCA2011-25 (2011).

12. A. Mutina A, D. Koroteev, Using X-ray microtomography for the three dimensional mapping of minerals. Microscopy and Analysis 139 (2012) 7-12.

13. S. Youssef, E. Rosenberg, H. Deschamps, R. Oughanem, E. Maire, R. Mokso, Oil ganglia dynamics in natural porous media during surfactant flooding captured by ultra-fast x-ray microtomography, International Symposium of the Society of Core Analysts held in Avignon, France, 11-18 September, (2014). paper SCA2014-023.

14. R. Oughanem, S. Youssef, D. Bauer, Y. Peysson, E. Maire, O. Vizika, A MultiScale Investigation of Pore Structure Impact on the Mobilization of Trapped Oil by Surfactant Injection, Transp Porous Med (2015) 109:673-692, DOI $10.1007 / \mathrm{s} 11242-015-0542-5$

15. S. Berg, H. Ott, S.A. Klapp, A. Schwing, R. Neiteler, N. Brussee, A. Makurat, L. Leu, F. Enzmann, J.O. Schwarz, M. Kersten, S. Irvine, M. Stampanoni, Real-time three-dimensional imaging of Haines jumps in porous media flow Proceedings of the National Academy of Sciences, 110(10) (2013), 3755-3759.

16. A. Georgiadis, S. Berg, G.; Maitland, A. Makurat, H Ott, Pore-Scale micro-CT Imaging: Non-Wetting Phase Cluster Size Distribution During Drainage and Imbibition, Physical Review E 88(3) (2013), 033002. 
17. H.V. Hill, J. Reisberg, G.L Stegemeier, Aqueous surfactant systems for oil recovery. Journal of Petroleum Technology, 25 (1973), 186-194.

18. C.D. McAuliffe, Crude-oil-in-water emulsions to improve fluid flow in an oil reservoir. Journal of Petroleum Technology, (1973), 721-726.

19. V. Alvarado, X. Wang, M Moradi, Role of Acid Components and Asphaltenes in Wyoming Water-in-Crude Oil Emulsions. Energy and Fuels, 25 (10) (2011), 46064613. DOI: 10.1021/ef2010805.

20. W.B.Bartels, M. Rücker, S. Berg, H. Mahani, A. Georgiadis, A. Fadili, N. Brussee, A. Coorn, H. van der Linde, C. Hinz, A. Jacob, C. Wagner, S. Henkel, F. Enzmann, A. Bonnin, M. Stampanoni, H. Ott, M. Blunt, S.M. Hassanizadeh, Fast X-Ray Micro-CT study of the Impact of Brine Salinity on the Pore-scale Fluid Distribution during Waterflooding, Petrophysics 58(1) (2017), 36-47.

21. L.W. Lake, Enhanced oil recovery, Prentice Hall, New Jersey, 1989.

22. E. Unsal, M. Broens, R.T. Armstrong, Pore Scale Dynamics of Microemulsion Formation. Langmuir, 32(28) (2016), 7096-7108.

23. M. Broens, E. Unsal, Emulsification kinetics during quasi-miscible flow in deadend pores. Advances in Water Resources, 113 (2018), 13-22. https://doi.org/10.1016/j.advwatres.2018.01.001.

24. D. Stauffer, A. Aharony, Introduction to Percolation Theory, Taylor \& Francis, 1994.

25. J.R. Barnes, H. Dirkzwager, J.R. Smit, A. On, R.C. Navarette, B.H. Ellison, M. Buijse, Application of internal olefin sulfonates and other surfactants to EOR. Part 1: Structure - performance relationships for selection at different reservoir conditions. SPE Improved Oil Recovery Symposium, 24-28 April, Tulsa, Oklahoma, USA. SPE-129766 (2010).

26. R.N. Healy, R.L. Reed, D.G. Stenmark, Multiphase microemulsion systems. SPE Journal, 16 (1976), 147-160. 
27. J.L. Salager, M. Bourrel, R.S. Schechter, W.H. Wade, Mixing rules for optimum phase behavior formulations of surfactant/oil/water systems. SPEJ, Soc. Pet. Eng. J., 19 (1979), 271-277.

28. J.L. Salager, A. Forgiarini, L. Marquez, A. Pena, A. Pizzino, M.P. Rodriguez, M. Rondon-Gonzalez, Using emulsion inversion in industrial processes. Advances in Colloid and Interface Science, 108 (2004), 259-272.

29. C. Huh, Interfacial tensions and solubilizing ability of a microemulsion phase that coexists with oil and brine. Journal of Colloid and Interface Science, 71(2) (1979), 408-426.

30. M. Rücker, S. Berg, R.T. Armstrong, A. Georgiadis, H. Ott, A. Schwing, R. Neiteler, N. Brussee, A. Makurat, L. Leu, M. Wolf, From connected pathway flow to ganglion dynamics. Geophysical Research Letters, 42(10) (2015), 38883894.

31. D. Paganin, S. Mayo, T. Gureyev, P. Miller, S. Wilkins, Simultaneous Phase and Amplitude Extraction from a Single Defocused Image of a Homogeneous Object. Journal of Microscopy, 206(1) (2002), 33-40. 15.

32. F. Marone, M. Stampanoni, Regridding Reconstruction Algorithm for Real-Time Tomographic Imaging. Journal of Synchrotron Radiation, 19 (2012), 1029- 1037.

33. D.A. DiCarlo, J.I.G. Cidoncha, C. Hickey, Acoustic measurements of pore scale displacements. Hydrology and Land Surface, 30 (2003). https://doi.org/10.1029/2003GL017811.

34. R.T. Armstrong, N. Evseev, D. Koroteev, S. Berg, Modeling the velocity field during Haines jumps in porous media, Advances in Water Resources, 77 (2015), 57-68. 
35. Y. Gao, Q. Lin, B. Bijeljic, M. Blunt, X-ray microtomography of intermittency in multiphase flow at steady state using a differential imaging method. Water Resources Research, 53(12) (2017), 10274-10292.

36. A. Buades, B. Coll, J.M. Morel, Nonlocal Image and Movie Denoising. International Journal of Computer Vision, 76(2) (2008), 123-139. doi:https://doi.org/10.1007/s11263-007-0052-1

37. A., Buades, B. Coll, J.M. Morel, A non-local algorithm for image denoising. Paper presented at the 2005 IEEE Computer Society Conference on Computer Vision and Pattern Recognition (CVPR'05), San Diego, CA, USA (2005).

38. W.F. Maddams, "The Scope and Limitations of Curve Fitting". Applied Spectroscopy. 34 (3) $(1980,245-267$.

39. W.E. Blass, G.W. Halsey, Deconvolution of Absorption Spectra. Academic Press (1981). ISBN 0121046508.).

40. J.R. Roof, 1970. Snap-off of oil droplets in water-wet pores. SPE Journal, 10 (1970), 85-90. 


\section{FIGURE CAPTIONS}

Figure 1 (A) Salinity scan of surfactant/oil/water system, B) micro-CT X-ray scan of optimum salinity Tube III.

Figure 2 A) Sketch of core sample (diameter $=4 \mathrm{~mm}$, height $=20 \mathrm{~mm}$ ). Field of view is $4 \mathrm{~mm}$ section, B) a vertical cross-section from three-dimensional pore space. Dry scan of the sandstone rock showing pore space (black) and grains (grey), C) three-dimensional pore visualization of field of interest.

Figure 3 Grey level histogram of the pore space for the waterflood (a) and the surfactant flood (b).

Figure 4 Calibration of average oil saturation vs. grey level in the micro-CT images during waterflood. A correlation was derived and was also used for processing the images of the surfactant flood.

Figure 5 a) Volume averaged oil saturation as a function of time during the waterflood and the surfactant flood. stretched (logarithmic) time interval during the first minute of surfactant injection shows a steep decrease in oil saturation in less than $1 \mathrm{PV}$ indicative for a mobilization mechanism. b) Two regimes observed in the oil saturation decay.

Figure 6 Grey level histograms for the first and last scan of the waterflood, and scans 1,2 , and 7 of the surfactant flood (Figure 5). 
Figure 7 Sequence of oil phase distribution in three-dimensional pore space over 1.3 min of water injection.

Figure 8 Scans of field of view during surfactant flood. Top row is the front view; three FOIs are marked (red, blue and black circles). Bottom row is the view from the top.

Figure 9 Close-ups of two FOI during surfactant flood for the fields of interest (FOI) A, B and C marked in Figure 8. 


\section{TABLES}

Table 1 Minerology of the Gildehauser rock sample.

\begin{tabular}{c|c|c|c|c} 
Illite \& mica & kaolinite & quartz & K feldspar & plagioclase \\
\hline trace & $2 \%$ & $94 \%$ & $3 \%$ & $1 \%$ \\
\hline
\end{tabular}

Table 2 Core sample properties.

\begin{tabular}{c|c|c|c|c} 
Rock & Porosity & Air Permeability & Core length & Core diameter \\
\hline Gildehauser sandstone & 0.2 & 1 Darcy & $20 \mathrm{~mm}$ & $4 \mathrm{~mm}$ \\
\hline
\end{tabular}

Table 3 Brine composition.

\begin{tabular}{c|c|c|c|c|c} 
Ion & $\mathrm{Na}^{+}$ & $\mathrm{K}^{+}$ & $\mathrm{Mg}^{2+}$ & $\mathrm{Ca}^{2+}$ & $\mathrm{Cl}^{-}$ \\
\hline$[\mathbf{m g} / \mathbf{L}]$ & 4270 & 7240 & 20 & 300 & 13750 \\
\hline
\end{tabular}


Table 4 Fluid properties of middle phasemicro emulsions at different salinities. IFT values were measured using spinning drop method and was between microemulsion phase and aqueous phase [21]. * due to inhomogeneous structure of the microemulsion, it was not possible to obtain a stable value for the viscosity in Tube I.

\begin{tabular}{l|c|c} 
& $\begin{array}{c}\text { Viscosity } \\
(\mathrm{mPa} . \mathrm{s})\end{array}$ & $\begin{array}{c}\text { IFT } \\
\left(\mathrm{mN} . \mathrm{m}^{-1}\right)\end{array}$ \\
\hline Tube I (micro)emulsion & $\sim 20^{*}$ & $1 \times 10^{-2}$ \\
\hline Tube II (micro)emulsion & 5 & $1 \times 10^{-2}$ \\
\hline Tube III (micro)emulsion & 4 & $2 \times 10^{-3}$ \\
\hline Tube VI (micro)emulsion & 6 & $1 \times 10^{-2}$ \\
\hline Brine / surfactant solution & 1 & - \\
\hline n-decane & 0.85 & - \\
\hline
\end{tabular}




\section{Supporting Material}

\section{Image processing}

Images obtained by micro-CT are often noisy. Noise and other imaging artefacts such as partial volume effects and beam hardening cause grey level histograms to consist of peaks with a finite grey level range even for fully homogenous phases. The main challenge of image processing is to identify either separate phases or materials based on grey level images. Figure 1 shows an example of Bentheimer rock dry scans, imaged by a benchtop micro-CT scanner with a much longer scanning time (10h) than in the surfactant flow experiment presented in this paper $(7 \mathrm{~s})$.

The respective histogram of the unfiltered image shows two broad peaks which are overlapping to some extent (Figure S1). After filtering with a 3D nonlocal means filter (3D NLM), the histogram shows two fully separated peaks which can be segmented by simple thresholding into a binary image, which then contains only two distinct lines, one for the darker pores and one for the brighter rock. 


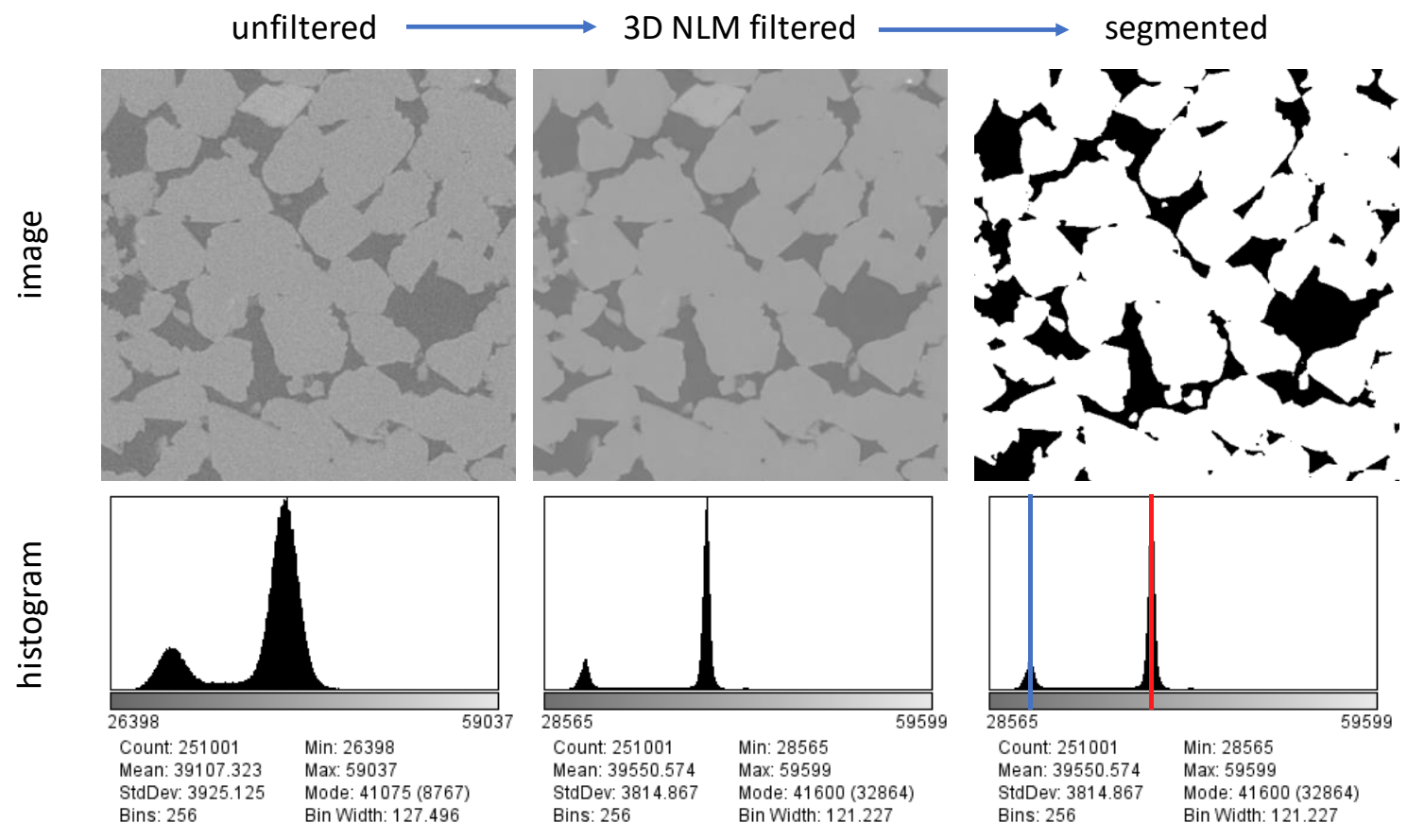

Figure S1 Illustration of how segmentation transforms a histogram with extended grey levels for each phase into a binary image with only two distinct grey values. Here an example of Bentheimer rock is shown, which has been scanned with a benchtop micro-CT scanner (Zeiss Versa 520) at a scanning time of 10h.

In most practical situations filtering can only reduce but not fully eliminate the histogram overlap. In these cases, region growing methods such as watershed segmentation or also machine learning based methods have been applied successfully [2].

\section{Segmentation of waterflood scans}

It would be intuitive to expect a specific grey value for water and another one for oil. However, instead of two single peaks, a range of grey values were detected during the waterflood (see Figure 3 of the article). This is common in micro-CT experimentation where multiple phases are involved and it is due to beam-hardening artefacts and partial volume effects at edges. For example, due to beam-hardening, the outer regions appear brighter than the center, even if the material is the same throughout [1]. The partial-volume effect occurs when multiple phases are present in a single voxel, which occurs for instance at grain boundaries. In addition, the X-ray intensity emitted by an X-ray tube fluctuates 
following a Poisson distribution which causes respective noise in the reconstructed 3D volumes. The combined effects cause for each material a distribution of grey levels which can overlap, depending on the overall signal-to-noise level. For segmentation, the images were filtered with a 3D nonlocal means filter which is an edge-preserving smoothing filter. This aids to separate the overlapping grey levels between different materials in the histogram to some extent [1] but the brine and oil peaks are still overlapping in our particular case because the signal-to-noise ratio is relatively low because of the fast scanning and respective short integration time of the CCD.

While the waterflood histogram has a bimodal structure, caused by overlapping water and oil phase peaks, during the surfactant flood the histogram becomes more continuous without any clear distinction. The main reasons for broad histogram peaks are image noise and partial volume effects. Due to the fast scanning the low signal-to-noise level is a major source of histogram peak broadening. However, even in imaging at significantly higher signal-to-noise levels, the peaks can still overlap due to partial volume effect. This effect is an imaging artefact in which a voxel gets assigned an intermediate grey value in case more than one phase occupy the space of a voxel during the time of recording. This effect may occur along interfaces where the imaged voxels may capture both phases and cause an intermediate appearance. These intermediate pixels can be easily identified as the neighbouring pixels display the corresponding phases accurately. It can also happen during fluid redistribution in dynamic (flow) experiments while an individual scan is taken, which can be identified by assessing the previous and latter image. If fluid redistribution is responsible for the grey value, there will be a gradual transition over time from oil to brine or vice versa. However, in the presented images in this article, many of the intermediate phase occurs at the same location in consecutive images. Therefore, continuous formation of emulsified phase would also contribute to the artefact.

For further interpretation the overlapping oil and brine peaks need to be deconvoluted. Deconvolution of overlapping peaks is a common practice in many areas of science and 
technology, such as spectroscopy [3,4]. In image processing, the most successful segmentation methods perform the deconvolution partially in the histogram and also in the spatial domain. Using the watershed segmentation method, the fluid compositions were segmented in the pore space using the peak values in the histograms as seed points. This takes advantage of the fact that in a micro-CT image with at least partially resolved features there is always a similar neighborhood separated by boundaries, which can be separated even though partially overlapping in the grey scale histogram - on the basis of a region growing method $[1,2]$.

\section{Time scales of emulsification}

The difference between early-time and late-time behaviour in oil displacement can be explained by examining emulsification processes in individual pores. In an earlier microfluidic study, emulsification of oil phase in dead-end pores was monitored using fluorescence microscopy technique [5]. By means of a solvatochromic dye, emulsified

phase could be distinguished from bulk oil and water. The pore space was composed of a sequence of oil saturated dead-end pores along a main flow channel in which the surfactant solution was injected. The same oil/surfactant/water system (different concentrations) as in the current study was used. Figure S2 shows the oil displacement in a dead-end pore during the injection of the surfactant solution (4\% C20-24 ENORDET® O, 5\% 2-butanol and $\mathrm{NaCl}$ ) into a dead-end pore. 


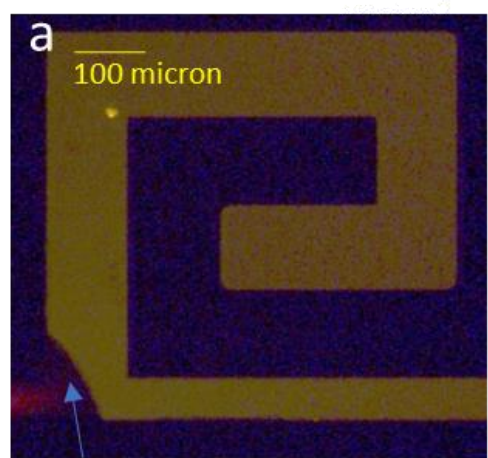

a. Surfactant solution sweeps off the oil at the pore entrance (convective flow)

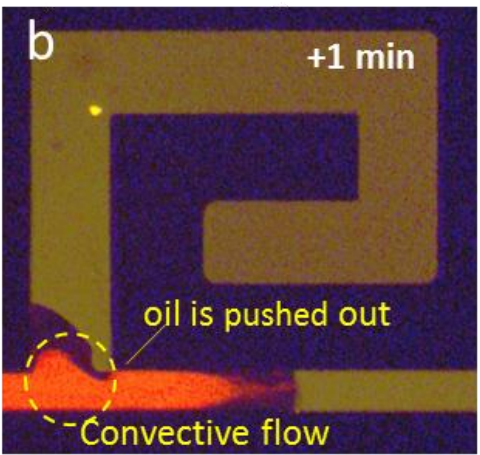

b. Surfactant solution advanced deeper in the pore and emulsification started.

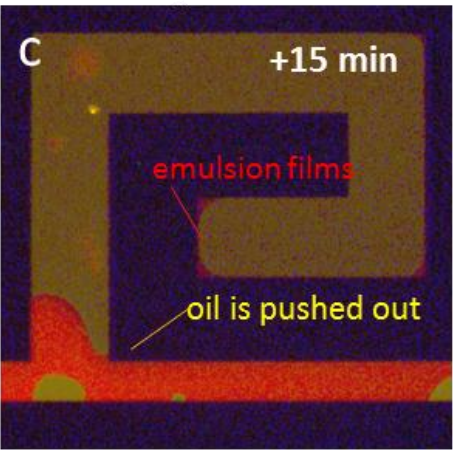

c. Oil mobilization slows down; emulsification occurs deeper in the pore far from main flow channel.

Figure S2 Surfactant solution injection at $100 \mathrm{~nL} . \mathrm{min}^{-1}$ flow rate. Salinity was $1.6 \% \mathrm{NaCl}$. Oil, water and emulsified phases under a) surfactant solution arrives at the pore sweeping some oil at the entrance (easy oil), b) 1 minute after image a; surfactant goes deeper in the pore, emulsification starts, c)15 min after image a; oil recovery slows done as emulsification advances away from main flow channel.

Two distinct regimes in oil mobilization were observed. In the first regime (early times), convective flow streams at the entrance of the dead-end swept the oil (Figure 2b). The flow field slightly extended into the channel, and generated mixing, consequently emulsification took place. The flow was from left to right in the main channel, therefore, the fluid pressure was the highest on the left corner of the dead-end opening and decreased towards right corner (Figure 2b, yellow circle). Consequently, this corner was the easiest exit point for the displaced fluid.

At later time, oil mobilization became slower. More oil was solubilized as the emulsification advanced deeper into the channel, but it was harder to push the emulsified oil out of the pore as it was deeper in the pore (Figure 2c). Furthermore, the viscosity of the emulsified phase was higher than the 'clean' oil phase and mobilization of more viscous emulsified phase required more effort. 
Another observation was that, at the very end of the dead-end channel, the angular corners were filled with red fluid. Emulsification ahead of the surfactant solution front was not unexpected: the glass micromodel was water-wet and it was probable that water films formed along the pore edges making the water phase fully connected [6]. Marangoni-driven spreading of the surfactant along the continuous water-oil interfaces may have provided with a sub-second transport mechanism for surfactant at the length scales of interest [7]. However, this also suggested that the injected surfactant solution was not only consumed at the emulsification front. The surfactant molecules could travel anywhere in the pore space as long as the water phase was connected. And this have not necessarily contributed to oil mobilization at the right place.

Transportation of fluids is controlled mainly by connected pores. Another type of pores that belongs to the class of interconnected pores but contribute very little to the flow, are dead-end pores or stagnant pockets. These pores have just a constricted opening to the flow path so the fluid in them is practically stagnant. In porous media applications where diffusion and dispersion processes are relevant, it is important to pay attention to the effects

of dead-end pores. The findings of this micromodel study can explain the mechanism that causes distinct early- and late-time behaviour in oil mobilization is rock samples.

\section{References:}

1. Schlüter, S.; Sheppard, A.; Brown, K.; Wildenschild, D. 2014. Image processing of multiphase images obtained via X-ray microtomography: a review. Water Resources Research, 50, 3615-3639.

2. S. Berg, N. Saxena, M. Schaik, C. Pradhan, Generation of Ground Truth Images to Validate Micro-CT Image Processing Pipelines, The Leading Edge 37(6) (2018), 412 420 .

3. W.F. Maddams, "The Scope and Limitations of Curve Fitting". Applied Spectroscopy. 34 (3) $(1980,245-267$. 
4. W.E. Blass, G.W. Halsey, Deconvolution of Absorption Spectra. Academic Press (1981). ISBN 0121046508.).

5. M. Broens, E. Unsal, Emulsification kinetics during quasi-miscible flow in deadend pores. Advances in Water Resources, 113 (2018), 13-22. https://doi.org/10.1016/j.advwatres.2018.01.001.

6. P. Hammond, E. Unsal, A Dynamic Pore Network Model for Oil Displacement by Wettability-Altering Surfactant Solution. Transport in Porous Media, 92 (2012). DOI: 10.1007/s11242-011-9933-4

7. S. Berg, Surfactant Spreading Along Liquid-Liquid Interfaces, Physics of Fluids 21 (3) (2009), 032105. 